\title{
Apuntes sobre algunos cambios semánticos de ciertos términos sociológicos
}

\author{
Ana Maria Gispert-Sauch Colls \\ Departamento Académico de Lingüistica
}

\begin{abstract}
C
omo miembro del equipo de la investigación sobre Comunicación, discurso y ciudadania, dirigida por la Dra. Sonia Luz Carrillo, en la Facultad de Letras y Ciencias Humanas de la UNMSM, indagué sobre el valor etimológico y semántico de una serie de términos, usados comúnmente en el discurso oral o escrito, en estudios o tratados sociológicos referidos a la comprensión y desarrollo de la participación ciudadana en nuestra sociedad actual. Presento a continuación, a modo de fichas de trabajo, algunos de estos vocablos cuyo significado ha pasado por un proceso de cambios, modificando -por enriquecimiento o contracción- el sentido primigenio. El orden de estas fichas obedece únicamente a una conveniencia, la que el mismo trabajo fue marcando a lo largo de su evolución.
\end{abstract}

Pueblo: Término que procede del latín populus. Era el conjunto de los ciudadanos romanos conplenitud de derechos: se dividiaen tres órdenes: patricios, caballeros y plebe.Integgadouscèn suls fresordenes; el populus gozaba de la soberania y de la majestad suprema. Es tradicionalmente famoso el lema emblemático de la República SENATUS POPULUSQUE ROMANUS (el senado y el pueblo romano) plasmado en siglas casi logotípicas como S.P.Q.R.

El término pueblo fue perdiendo, en determinados contextos, este valor de totalidad y pasó a señalar únicamente una parte de ella: la plebe. Se aplica al término pueblo lo que era una parte de él.

En el siglo XVIII se acepta ya el valor peyorativo de pueblo como opuesto a las elites dirigentes, cultas; surge la palabra netamente despectiva populacho. Contrariamente, el cultismo popular, aparecido ya en el siglo XV, fue usado entonces especialmente para adjetivar las manifestaciones artisticas y culturales formadas por el espíritu de una colectividad. 
Hoy día, en el lenguaje común, lo popular puede oponerse a lo exclusivo, a lo elitista ( ¿no sigue, acaso, este mismo camino demasiadas veces en la práctica el término de origen germano folklórico, sinónimo de popular?). En ocasiones popular adquiere una valoración negativa y se convierte en equivalente de vulgar, en su acepción secundaria. Pero, simultáneamente, el término pueblo recobra su importancia en las sociedades democráticas, recuperando en parte, y casi exageradamente, el valor del aforismo antiguo: vox populi, vox Dei, según los intereses politicos que estén en juego.

Masa: Dejado a un lado el sentido que asignan al término los físicos, en el ámbito sociológico, esta palabra, que viene del latín massa, tiene el valor de montón, hacinamiento, referido primordialmente a objetos o cosas. (No resulta tan banal el permitir que la imaginación nos lleve libremente por los terrenos de la vida cotidiana hacia donde nos sugiera la palabra). El valor semántico moderno, siempre dentro del campo sociológico, se ha desplazado hacia las personas, con el sentido genérico de "gente", perô con la característica de gente indiferenciada, donde no cuentan las caracteristicas comunes que prevalecen en el término "grupo".

De ahí surge el derivado masivo, como perteneciente o relativo a la masa. Hay que señalar que, usado en singular, el término masa precisa de un complemento adjetivo o un determinativo con "de": (ej. masa de oro, masa humana etc.); pero, usado en plural, se refiere generalmente a personas: ej. las masas permanecieron largotierno escuchando.e Letras

\section{"Jorge Puccinelli Converso»}

Ciudad: término muy importante en el mundo latino. Su origen etimológico es civitas, que tiene el significado de ciudad en tanto que conjunto de ciudadanos. Ciudad era una asociación política independiente y autónoma, que se administraba por sí misma, mediante sus magistrados y asambleas. Los grupos de personas no unidas por estos lazos politicos a instituciones no formaban la ciudad, sino simplemente eran una multitudo.

En cambio, la ciudad en tanto que lugar donde vivian los habitantes, sus casas, palacios, calles, edificios y plazas, recibía el nombre de urbs. Tanto asi que, en los textos clásicos latinos, la ciudad de Roma es denominada Urbs, la ciudad por antonomasia.

Ciudadano: procede de civis, de la misma raíz que civitas. Se trata del sujeto de los derechos ciudadanos existentes en Roma, desde el siglo II a. C. 
hasta el Ill p. C. en una organización genuina, aunque tomó prestados elementos diversos de legislaciones extranjeras. Estos derechos podían ser públicos: derecho a votar, a ser votado para cargos públicos, a apelar al pueblo contra la sentencia de un magistrado; los derechos privados eran el de poseer bienes, comprar, vender, y el derecho a contraer matrimonio legal.

En un comienzo, en Roma, los únicos ciudadanos eran los patricios. Posteriormente, el uso de la palabra civis se hace extensivo a los plebeyos y, en el s. I a.C., se extiende hasta comprender a quienes pertenecen a las provincias $\mathbf{u}$ otras ciudades del Lacio. En el siglo II], con el emperador Caracalla, se concede el carácter de civis a todos los habitantes del Imperio. No resulta muy desatinado, cuando se quiere expresar lo que significaba este título, pensar en lo que actualmente supone la posesión de un pasaporte norteamericano o europeo. Los esclavos no eran considerados ciudadanos, por ser personas no libres.

Cabe señalar cómo en castellano diferenciamos también los derivados de ambos términos, dando a urbe, urbanización, urbanismo (la excepción es urbanidad, aunque se refiere también al aspecto externo pero sólo del comportamiento humano...) un valor referente al aspecto externo de la ciudad; correspondientemente, ciudadano, ciudadaní, civismo, civil, civilidad, civilización son palabras con un valor referencial al habitante de esa urbe.

Hoy el término ciudadania sugiere un matiz político, como indicativo de una fuente de derechos, Zos quessustentan la participación activa y pasiva de cada individuo en la organización social de la forma de yida de los ciudadanos en cuanto tales, quienes poseen intereses comunes dentro del mismo territorio de la ciudad, con la conciencia de pertenecer a un cuerpo organizado. Ejercer la ciudadania, si bien es un "derecho" de todos, supone tener conocimiento de tal derecho y contar con el acceso a los medios que permitan plasmar teórica y prácticamente las opciones colectivas del conjunto de los habitantes.

Nación: del latín natio; este término remite etimológicamente a la misma raiz del verbo nacer, en latín nasci. Aparece en el siglo XV con un valor equivalente en la práctica a raza pueblo en sentido amplio, refiriéndose a los que, habiendo nacido en un mismo lugar, comparten un destino común. En la edad modema, con el surgimiento de los Estados, se comienza por vez primera en la historia a hablar de nación como casi sinónimo de Estado, y también de pais. La nación supone fronteras geográficas que la encierran, con todas sus consecuencias juridicas consecuentes, en un espacio y expresa una identidad determinada con sus consecuencias culturales. 
Etnia: del griego ethnós, ethnous. Tiene también un valor semántico de raza, pueblo, pero incluye una perspectiva más cultural que política. En la etnia se prioriza sobre todo la lengua, ritos, creencias, cosmovisión, valores y costumbres de un grupo con características propias, distinto a otros grupos. En esta diferencia pueden estar también las caracteristicas externas de los miembros (color, estatura, conformación fisiológica etc.) aunque a éstas las representa mejor la palabra "raza". En nuestra lengua, la aparición del término etnia y sus derivados étnico/a data del siglo XVII.

Identidad: palabra surgida del latín tardio identitas, es en realidad un derivado de idem (el mismo, o lo mismo) + entitas (entidad-del participio de presente del verbo ser: lo que es-). Viene a ser la igualdad de una persona o cosa con lo que ella misma es; igual e idéntico no son propiamente equivalentes. Sin embargo, como deciamos al hablar de nación, en el contexto sociopolítico y cultural moderno, el término identidad expresa la coherencia de una persona o grupo con sus propias raíces. Si bien el adjetivo derivado "idéntico" alude, en el lenguaje común, a semejanza, igualdad o parecido entre seres o cosas, el sustantivo identidad se ha enriquecido con un referente casi metafísico, que expresa lo más propio y profundo de una persona, grupo o comunidad. En la identidad hay un aspecto dado (como en nación = nacido en un lugar), y un aspecto volitivo el que depende de la aceptación voluntaria de las distintas realidades que comporta el origen propio o el de la comunidad o grupo.

\section{Biblioteca de Letras}

Pertenencia: sustantivo que en el siglo XISdhace ya alusión al acto de tener asido, tener ocupado. Formado de per (valor intensivo) + el verbo tenere, indica la relación de un objeto con respecto a una persona, la cual tiene sobre dicho objeto una especie de derecho adquirido, o derecho de propiedad, por la que el objeto en cuestión no puede ser robado o transferido sin más a otros. Pero el concepto de pertenencia es más amplio, pues no queda restringido a un derecho personal sobre las cosas. Siempre tratándose de entes no personales, abstractos incluso, cabe hablar de pertenencias. Es éste el caso cuando, en medio de un discurso, aludimos a una cuestión diciendo que "resulta pertinente" (per + tenere, la misma etimología) la alusión a la misma. Lo que, en ese caso, estamos afirmando es que dicha cuestión "pertenece" al conjunto del discurso.

Por último, el concepto de pertenencia puede encontrarse también referido a una característica de ciertas personas, la que indica su inclusión en un conjunto mayor, sea éste una institución, cuerpo o colectivo de cualquier especie. Por el hecho de tratarse de un aspecto personal, será lógico suponer como 
inherente a esta pertenencia la conciencia y voluntad del sujeto "perteneciente" al tal conjunto.

Voluntad: sustantivo derivado del verbo latino volo, que significa yo quiero, deseo. Aparece ya en el siglo X, y es uno de los vocablos que ha ido enriqueciéndose de manera asombrosa con el transcurso del tiempo, sobre todo a través de la escolástica y las distintas escuelas filosóficas. Desde significar la facultad de gobierno que tienen los humanos, hasta tener el valor que otorgamos a la expresión "buena voluntad" (la que contiene una referencia al consentimiento prestado a algo), hay toda una gama de matices que transitan por lo intelectivo y lo afectivo (no es gratuito el uso que hacemos del verbo "querer" para expresar el afecto).

A modo de ejemplo, podemos decir que, para Agustín de Hipona, la voluntad es el deseo de lo inteligible y lo bueno reflejado en el alma humana. Para Hobbes, en el siglo XIX, la voluntad es tan sólo un impulso mecánico de atracción o repulsión hacia algo o alguien (equivaldría al término "deseo", "apetencia" etc.).

En el contexto actual, la palabra yoluntad tiene, con frecuencia, un valor semántico que comprende los campos racionales y afectivos, con cierta predominancia del sentimiento. En este aspecto, la palabra se encuentra en nuestros medios más cercana al sentido que le otorgaba Rousseau.

La voluntad puede ser individual o colectiva, o incluso institucional, como cuando en el discurso thablado usamos ta expresfon "Voluntad política". Esta expresión "voluntad colectiva" tiene un valor semántico ligado a un quehacer, a un compromiso que atañe a los miembros de un conjunto en su totalidad. La voluntad, entonces, está expresada en su potencialidad a la vez intelectual y afectiva.

Público: en su sentido primigenio latino, es un adjetivo que significa lo que pertenece al Estado, o evoca la dedicación a los asuntos políticos (propios de las polis). Aquí tiene su fundamento el significado de "conocido por todos" (no solamente de hecho, por cierto, sino también jurídicamente y, por lo mismo, "oficial"), en oposición al término privado, que hace referencia a la familia o al individuo que no ejerce magistraturas ni cargos políticos.

Cuando, en el lenguaje común, se habla de público (como sustantivo) se alude al grupo de personas que asiste a un acto o espectáculo, y es prácticamente 
sinónimo de grupo. Hablar de "público en general" es una redundancia, ya que "general" expresa, en estos casos, justamente, que se trata de una cualidad común en un colectivo.

Alteridad: Viene de alter (otro). Es palabra, pues, que porta en su entraña la referencia a los otros, a los demás. Semánticamente alude al reconocimiento de todo tipo de diferencias: carácter, ideas, afiliación politica o religiosa, género, edad, clases, raza, identidad y hábitos culturales. La interculturalidad -de la que actualmente se habla con frecuencia- es una de las múltiples áreas que comprende la alteridad, y se refiere especificamente a las diferencias de identidad y hábitos culturales.

Para que una referencia o relación con el "otro" sea posible se precisan dos polos: el de la propia identidad, fundada sobre un "yo" o un "nosotros", y el de la alteridad cuya base puede definirse como un "otro" u "otros" diferentes.

Cuando alguien se altera, quiere decir etimológicamente que se ha convertido en "otro" distinto a su propia identidad. Paralelamente, una alternativa viene a ser "otra" via que se-ofrece como propuesta posible. En todo caso, la palabra que nos ocupa siempre juega con lo diferente como concepto infaltable en su dinámica expresiva.

Sociedad: aparece este término en la primera mitad del siglo XIII, derivado

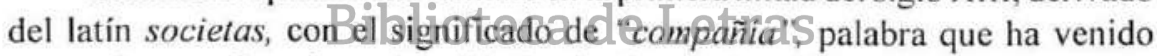
cargando, con cierta intẹnçionalịdadọsin lélląmaticessfrecuentemente militares (dos siglos más tarde la Societas lesu se conocerá como "Compañia de Jesús", y sus miembros han sido vistos alternativamente como soldados o compañeros, conforme a diferentes apreciaciones).

El significado original de sociedad (grupo de personas que conviven y se acompañan entre si) se amplió cuantitativamente, llegando a significar hoy día el conjunto de personas que forma un pais, una nación o hasta un continente en un período determinado (ej. sociedad medieval, sociedad moderna etc.). De estas personas, si bien conviven en un territorio o lugar geográfico común en un tiempo específico, no puede afirmarse que mantengan relaciones directas entre sí.

El adjetivo derivado sociable alude semánticamente a la manera de comportarse en general, acorde con características de alguna forma comunes a un grupo de personas. Así se entiende que tildemos de "insociable" a quien no se 
comporta como cabría esperar de alguien que físicamente convive con personas de costumbres determinadas.

Persona: El término es de origen etrusco. Se refería a las máscaras utilizadas en el teatro, las cuales tenian doble finalidad: la de representar al personaje que le correspondia al actor $\mathrm{y}$, a la vez, la de dar mayor sonoridad a las palabras (per-sonare), pues la máscara hacía las veces de una especie de megáfono, dirigiendo la voz hacia el numeroso público situado en espacios abiertos.

En el derecho romano, recibió el nombre de persona todo ser o entidad susceptible de derechos y obligaciones, o sea, juridicamente capaz. En la sociedad romana no todos los hombres eran "personas". Los esclavos, por ejemplo, carecian de capacidad jurídica, no eran personas. Entre los ciudadanos libres, solo el pater familias gozaba de plena capacidad jurídica. Por tanto, para ser persona en el pleno sentido de la palabra, habia que ser ciudadano, libre y pater familias.

En el siglo XIII aparece el derivado "personaje", que alude al papel o función que cumple la persona más que a ella en sí misma, hasta el punto que pueden llegar a ser antagónicos la persona y el personaje.

Semánticamente esta palabra ha ampliado su significado, y lo ha enriquecido con una connotación adicional a la autoconciencia de poseer características diferentes a las de otros. Êstees êfalor-que mantiene el derivado "personal", palabra banalizada én fa actualidad auahido seututizacomo sustantivo para designar al conjunto de operarios en una empresa.

Anonimato: procede de $a$ (privativa) $+n$ (eufónica) +onoma (=nombre). Su valor etimológico es "aquello que carece de nombre". De ahí pasa a ser empleada la palabra, con su forma derivada anónimo, para expresar específicamente la autoría desconocida. El anonimato viene a ser el antivalor de lo personal cuando niega su más preciada característica que es la identidad. En efecto, el "nombre" en la tradición semita, también en la griega y, en parte, en la romana, designaba algo esencial de la persona, o su función en la sociedad. Carecer de nombre es carecer de identidad, no ser persona. Hoy día, el anonimato está ligado a las actuaciones masivas donde es difícil percibir las características propias de cada uno.

Anomia: vocablo formado por $a$ (privativa) + nomos (ley, uso, costumbre). Es un neologismo moderno para expresar la falta de normas, pautas, reglamentos, 
orden o leyes en el comportamiento colectivo. En realidad, no expresa la falta de tales leyes o principios sino la prescindencia de ellos en la actuación de ciertos grupos sociales.

A menudo, por una falta de comprensión etimológica, se ha confundido el significado de anomia con el de anonimato analizado anteriormente; sin embargo, tanto etimológica como semánticamente son dos términos completamente distintos.

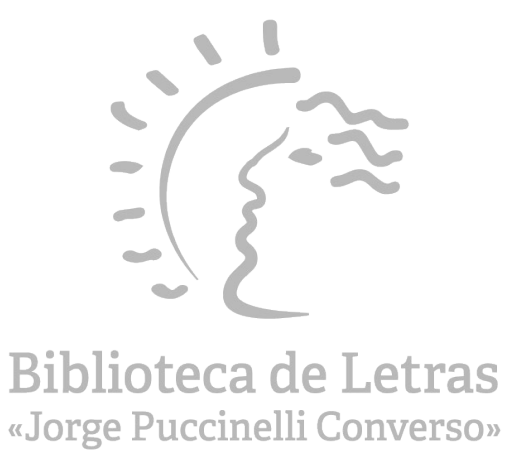

